University of Nebraska - Lincoln

DigitalCommons@University of Nebraska - Lincoln

Faculty Publications, Department of Psychology

Psychology, Department of

August 2006

\title{
Adolescent Perceptions of Appropriate Parental Reactions in Moral and Conventional Social Domains
}

Laura M. Padilla-Walker

Brigham Young University, laura_walker@byu.edu

Gustavo Carlo

University of Nebraska-Lincoln, carlog@missouri.edu

Follow this and additional works at: https://digitalcommons.unl.edu/psychfacpub

Part of the Psychiatry and Psychology Commons

Padilla-Walker, Laura M. and Carlo, Gustavo, "Adolescent Perceptions of Appropriate Parental Reactions in Moral and Conventional Social Domains" (2006). Faculty Publications, Department of Psychology. 34.

https://digitalcommons.unl.edu/psychfacpub/34

This Article is brought to you for free and open access by the Psychology, Department of at DigitalCommons@University of Nebraska - Lincoln. It has been accepted for inclusion in Faculty Publications, Department of Psychology by an authorized administrator of DigitalCommons@University of Nebraska - Lincoln. 


\title{
Adolescent Perceptions of Appropriate Parental Reactions in Moral and Conventional Social Domains
}

\author{
Laura M. Padilla-Walker, Brigham Young University \\ Gustavo Carlo, University of Nebraska-Lincoln
}

\begin{abstract}
Research suggests that adolescents' ratings of the appropriateness of parental reactions are influenced by several constructs, including adolescents' perceptions of the type of parental reaction, the emotions felt by the adolescent and parental intentions. However, little is known regarding how these constructs are differentially predictive of appropriateness in different socialization contexts. One hundred and twenty-two adolescents (mean age $=16.87$ years) answered questions regarding past situations in antisocial and prosocial contexts, and in moral and conventional domains. Different parental reactions were reported across moral and conventional domains. In addition, the appropriateness of parental responses varied across domain. Namely, in antisocial contexts, parental responses of yelling and punishing were seen as more appropriate in moral than conventional domains. In prosocial contexts, no action from the parent was seen as less appropriate in conventional than moral domains. In addition, adolescents' perceptions were more strongly associated with adolescents' ratings of appropriateness in conventional than moral social domains. These findings highlight the importance of considering both moral context and social domain when examining adolescents' perceptions of appropriate parental reactions and internalization of values.
\end{abstract}

Keywords: context; appropriateness; values; adolescence

Research on parenting practices as they relate to adolescents' internalization of values and behavior has largely focused on children's behavior in antisocial or transgressive contexts. However, scholars have noted the importance of examining adolescent behaviors in prosocial or positive contexts as well (Carlo, 2006; Grusec, Goodnow \& Kuczynski, 2000). Within antisocial contexts, researchers have examined different types (or domains) of behavior, such as moral, conventional, prudential and personal domains (Turiel, 1998). Research suggests that parents and children respond differently, for example, to transgressions of moral values (e.g., honesty) than conventional values (e.g., table manners). Although there is a great deal of research examining different domains of behavior in antisocial contexts, there is little research examining different domains in prosocial contexts (for reviews, see Smetana, 1995; Turiel, 1998). Thus, the current study examined adoles-

Correspondence should be addressed to Laura Padilla-Walker, 2097 JFSB, School of Family Life, Brigham Young University, Provo, UT 84602, USA. Email: laura_walker@byu.edu

Published in Social Development 15:3 (August 2006), pp. 480-500. Copyright (C) 2006 Blackwell Publishing Ltd. Used by permission. 'The definitive version is available at www.blackwell-synergy.com." 
cents' perceptions of the appropriateness of parental reactions during parent-child interactions in both antisocial and prosocial contexts and moral and conventional domains.

An adolescent's understanding and acceptance of values is a complex process that is influenced by many variables. Grusec and Goodnow (1994) proposed a model that considers a number of variables hypothesized to influence the process of values internalization. They suggested that before values are acquired, children must accurately perceive the parental message and must accept the parental message. The child's acceptance of the parental message is partly determined by whether the child perceives the parental reaction to be appropriate, which includes how well the parental reaction fits the misdeed.

Although little research has directly examined the role of adolescents' perceptions of appropriate parental reactions in the process of values internalization, Grusec and Goodnow (1994) maintain that children find parental reasoning that is similar to their own as more acceptable than reasoning that is dissimilar, and will thus be more likely to attend to the message. For example, Eisenberg-Berg and Geisheker (1979) found that empathyoriented reasoning was more effective than norm-oriented reasoning in promoting sharing behavior in young children. This is consistent with notions of appropriateness because empathy-oriented reasoning is closer to the type of reasoning that children use when justifying sharing behavior (e.g., 'it makes others feel good when you share'), and thus may be more readily attended to by children (Grusec \& Goodnow, 1994). In addition, a few recent studies have examined adolescents' ratings of appropriate parental reactions and how they relate to adolescents' behavior and the process of values internalization (Padilla-Walker \& Carlo, 2004; Wyatt \& Carlo, 2002).

Wyatt and Carlo (2002) examined whether adolescents' expectations regarding appropriate parental reactions were predictive of adolescents' antisocial and prosocial behavior. These researchers found that adolescents' views of parental appropriateness were more strongly related to parental responses in prosocial contexts than in antisocial contexts. In other words, adolescents were more likely to behave prosocially and less likely to behave antisocially if they perceived their parents' reactions to prosocial behaviors to be appropriate, suggesting that adolescents hold different standards for parental reactions depending on the context in which their own (the adolescents') behavior occurs.

Another study examined aspects of the parent-child interaction that were associated with perceptions of appropriateness in both prosocial and antisocial situations (PadillaWalker \& Carlo, 2004). This study suggested that adolescents' perceptions of how parents react to specific situations, the emotions felt by adolescents during interactions and the intentions of parents were all associated with adolescents' perceptions of appropriateness. Taken together, these findings place particular emphasis on the pro-social context and suggest utility in examining not only parental reactions as they relate to appropriateness, but also other aspects of the parent-child interaction, such as adolescent emotions and parental intent. These studies also provide support for Grusec and Goodnow's (1994) model and the importance of appropriateness in the process of values internalization.

\section{Social Domain}

Although it is important to examine differences in adolescents' ratings of the appropriateness of parental reactions in antisocial and prosocial contexts, another way to examine how appropriateness might vary by context is to consider the social domain of the be- 
havior. Research suggests that the most effective discipline is discipline that matches the child's misdeed, or action (Grusec \& Goodnow, 1994). Types of misdeeds are often differentiated based on the social domain perspective, which suggests that parental socialization goals reside within a number of coexisting domains (e.g., personal, conventional, prudential, moral), and that each domain should be considered when parental behavior is explored (Nucci, 1981, 1996; Smetana, 1997; Turiel, 1983, 1998). Actions in the personal domain have been defined as relating only to the individual and entail preference and choice regarding such issues as friends, the state of one's body and privacy. Actions in the conventional domain have been defined as arbitrary actions (e.g., raising your hand in class) that co-ordinate how individuals interact and provide a set of agreed-upon expectations regarding how to behave properly. Actions in the prudential domain are those related to the child's safety or well-being. Actions in the moral domain are based on concepts of trust (e.g., lying, cheating), justice and rights; and reflect individual understanding of how people ought to behave towards one another (Smetana, 1997). Although we are unaware of any research directly examining appropriateness of parental reactions as a function of social domain, research concluding that children rate their teachers' domain-appropriate behavior higher than domain-inappropriate behavior (Nucci, 1984) suggests that adolescents' will perceive parental reactions to adolescent behavior as more appropriate if the reactions are domain-appropriate than if they are domain-inappropriate.

To gain a more complete understanding of parental reactions to adolescent behavior, social domain theorists argue that we must be more accurately informed of the type of behavior parents are responding to. By the same token, social domain theorists would suggest that when assessing adolescents' perceptions of the parent-child interaction, it is also important to understand what type of parental behavior adolescents are responding to and the social domain in which the behavior takes place (Killen, Lee-Kim, McGlothlin \& Stangor, 2002). The current study focused on two domains that are often compared by social domain theorists; the moral domain and the conventional domain.

\section{Antisocial or Transgressive Contexts}

A great deal of research has been done in support of the notion that children and parents commonly distinguish between transgressions in moral and conventional domains (Bersoff \& Miller, 1993; Smetana, Bridgeman \& Turiel, 1983; Tisak \& Turiel, 1988; for reviews, see Helwig, Tisak \& Turiel, 1990; Smetana, 1995; Tisak, 1995; Turiel, 1998). These studies consistently find that children and adolescents see moral transgressions as issues of obligation, issues that are in need of regulation, and standards that should remain even if the rules to enforce them are removed. In contrast, conventional transgressions are more often seen as somewhat arbitrary issues that are contingent upon rules and social regulations (Tisak \& Turiel, 1988). Further, children and adults have been found to react differently to moral transgressions than to conventional transgressions, with the focus being on the needs and welfare of others in the moral domain, and rules and social order in the conventional domain.

Although domain theorists do not typically examine the domain-appropriateness of specific parental reactions, there is much to be gained by examining how research on parental reactions (or parenting practices) applies to domain theory. Although we might expect parental reactions that focus on the impact of adolescents' actions to be perceived as 
more appropriate in moral domains and parental reactions that focus on norms and parental expectations to be more appropriate in conventional domains (Turiel, 1998), the current study adds to the existing literature by instead examining how parents communicate their message (e.g., yelling, talking, preaching) and whether adolescents view these specific parental reactions as more or less appropriate as a function of the domain in which the transgression occurs. In other words, in transgressive contexts adolescents may view strong parental reactions as more appropriate in moral domains than conventional domains, as strong parental reactions may be perceived as more domain-appropriate in response to transgressions of obligatory values (e.g., kindness) versus values that are seen by the adolescent as more arbitrary (e.g., household rules). Indeed, research suggests that adolescents feel their parents are justified in regulating their behaviors in moral domains and usually accept parental authority in the moral domain more readily than in the conventional domain (Smetana, 1988, 1995).

\section{Prosocial or Positive Contexts}

Although there has been a great deal of research examining domains of social judgment in antisocial or transgressive contexts, there has been little research by domain theorists focusing on prosocial or positive contexts. It is logical to assume that children might expect different parental reactions in response to prosocial behavior in the moral domain (e.g., helping someone in need) than they would in response to prosocial behavior in the conventional domain (e.g., voluntarily completing household chores). One study (Smetana et al., 1983) showed that when fifth, eighth and eleventh graders were asked to rank behavior based on degree of 'wrongness', negative moral behavior (such as cheating) was consistently ranked as more wrong than negative conventional behavior (such as coming into class late), and positive moral behavior (such as sharing) was consistently seen as more right than positive conventional behaviors (such as raising your hand). The authors concluded that this study provided support for the idea that children and adolescents consistently make distinctions between right and wrong based on social domain, regardless of the positive or negative context in which the behavior occurs.

Based on this research, we would expect adolescents to make distinctions between moral and conventional domains in prosocial contexts similar to those made in antisocial contexts. However, the study by Smetana et al. (1983) tells us little regarding how these distinctions might be related to adolescents' perceptions of appropriate parental reactions. Although adolescents may perceive different parental reactions across domains, the question still remains whether adolescents' hold similar standards for the appropriateness of parental reactions in moral and conventional domains in both antisocial and prosocial contexts. In other words, although adolescents may perceive greater amounts of parental yelling in moral domains than conventional domains (regardless of context), do adolescents see parental yelling as more appropriate in moral than conventional domains in both antisocial and prosocial contexts? Although there is no direct research to support specific hypotheses, there is research suggesting that adolescents' views of appropriate parental reactions by domain may function differently in prosocial contexts than in antisocial contexts. For example, research suggests that children expect greater amounts of praise for behavior that is considered conventional or discretionary than they do for behavior that is considered moral, or obligatory (Kahn, 1992). Based on this finding, adolescents might place 
special importance on the conventional domain in prosocial situations and find a lack of praise (e.g., no response on the part of the parent) less acceptable in response to conventional or arbitrary acts of kindness than they would for obligatory or expected acts.

\section{Hypotheses}

The present study was a re-analysis of the Padilla-Walker and Carlo (2004) dataset. The goal was to examine whether adolescents' perceptions of parental reactions during parent-child interactions differed across moral and conventional social domains. Based on social domain theory and past research on appropriateness, we expected that adolescents would report differences in parental reaction, adolescent emotion and parental intent in moral and conventional domains in both antisocial and prosocial contexts. For example, higher reports of parental power assertion and adolescent guilt and lower reports of adolescent anger were expected in antisocial moral domains than conventional domains (given the obligatory nature of the moral domain). Based on research suggesting that children expect more praise in response to arbitrary acts (Kahn, 1992), we also expected higher reports of verbal praise and positive emotions in prosocial conventional domains than moral domains.

It was difficult to make specific hypotheses regarding differences in adolescent emotion and parental intent as a function of domain because we are unaware of any research directly examining these constructs in moral and conventional domains. However, based on research suggesting that the emotions felt by adolescents and adolescents' perceptions of parental intentions are related to appropriateness (Padilla-Walker \& Carlo, 2004), the current study examined how adolescents' perceptions of their own emotions and their parent's intentions differed as a function of domain. Not only did we expect adolescents to report differences in their perceptions of the parent- child interaction as a function of domain, we also expected that adolescent rating of parental reactions as more or less appropriate would differ between domains. More specifically, we expected that power-assertive parental reactions (e.g., yelling, punishment) would be seen as more appropriate in moral domains than in conventional domains (Smetana, 1988, 1995). We also expected that although parental praise was likely to be seen as appropriate across domains, adolescents might feel entitled to praise in response to discretionary or conventional prosocial actions (Kahn, 1992). For this reason, a parental response of no action may be seen as less appropriate in conventional domains than moral domains. Finally, although we found it difficult to make specific hypotheses due to limited research on appropriateness, we explored whether parental reaction, adolescent emotion and parental intent were differentially associated with appropriateness in moral and conventional social domains.

\section{Method}

\section{Participants}

One hundred twenty-two adolescents (mean age $=16.87$ years, $\mathrm{SD}=.80$ ) from a public high school in a mid-sized community in the midwest region of the USA. participated in the study. Most of the adolescents (92 percent) were European-American and there were slightly more males $(n=64)$ than females. The majority of the adolescents lived with both 
their parents (78 percent), 37 percent reported being firstborn children and 38 percent reported being second-born. Over half ( 55 percent) of mothers and fathers ( 57 percent) had a four-year college degree or higher. The mean combined parental income was between $\$ 30,000$ and $\$ 49,000$ per year, ranging from less than $\$ 10,000$ to $\$ 100,000$ and higher.

\section{Procedures}

Sixty-four teachers in a local high school were given letters requesting that they allow their students to participate in the study. Of the 35 teachers who agreed to allow their classes to participate, seven classrooms were randomly selected to complete the study. After obtaining informed consent from parents, researchers administered questionnaires to the students during class and collected them at the end of class. Half the students were asked to fill out the questionnaire regarding their father's past reactions and the other half were instructed to fill out the questionnaire regarding their mother's past reactions. Due to the open-ended nature of the questionnaire, halfway through the procedure, adolescents were given a number of demographic questions to allow for a break.

\section{Materials}

The adolescents completed a number of demographic questions, including questions regarding their age, gender, race, parental income and education, religious attendance, scholastic achievement and extracurricular activities. They then completed an open-ended questionnaire devised for this study, as described below.

Appropriateness of Parental Reaction. The adolescents were asked to rate their parent's reactions regarding their (the adolescents') antisocial and prosocial behavior. The questionnaire consisted of eight vignettes, each asking the adolescent to read a hypothetical situation and then report on a similar real-life interaction they had in the past six months with their parent.

Four of the hypothetical vignettes were in antisocial contexts and four were in prosocial contexts. For example, one of the vignettes regarding past parental reactions in an antisocial context asked adolescents to 'Think of an instance in the past six months when you have been caught lying to your parent'. One of the prosocial vignettes asked adolescents to 'Think of an instance in the past six months when you have helped out a friend who was in trouble and could not help themselves, and your parent found out'. In addition, two of each of the antisocial (e.g., cheating) and prosocial (e.g., helping a friend) vignettes dealt with situations that could be classified as in the moral domain, and two of each of the antisocial (e.g., breaking curfew) and prosocial (e.g., doing household chores voluntarily) vignettes dealt with situations that could be classified as in the conventional domain.

Each vignette consisted of four open-ended questions: (1) What was your parent's reaction? (2) How did you feel when your parent reacted this way? (3) Why did you feel this way? (4) What do you think your parent's intentions were? After reporting on their parent's reaction, the adolescents were asked to rate the appropriateness of their parent's reaction to the past real-life event on a five-point scale, with values ranging from 1 ('very inappropriate') to 5 ('very appropriate'). During final coding, vignette six (a prosocial moral vignette) was excluded from analysis because the majority of participants misinter- 
preted the prosocial act as an antisocial act (the vignette involved admitting the truth even when there might be negative consequences), resulting in data that were inconsistent with the other three prosocial vignettes. Thus, we performed the final analyses on four antisocial vignettes and three prosocial vignettes.

\section{Coding}

We identified common codes based on the frequency of adolescent responses. We coded 40 questionnaires exhaustively. Coded categories that were present over 25 percent of the time in these 40 questionnaires acted as the final codes for the remainder of the questionnaires. Each open-ended question was then coded as either 0 ('not present') or 1 ('clearly present') for the theme corresponding to that given question. A naïve coder scored 20 questionnaires to assess inter-rater reliability. Kappa values ranged from .72 to 1.00. This resulted in a mean kappa of .93 across the final 11 coding categories for all seven vignettes (77 total codes). Kappa values below .90 were discussed, specific coding guidelines were reviewed and coding was modified in accordance with the guidelines (see Table 1 for final coding categories).

Parental Reaction. We coded parental reaction for parental response or discipline strategy. Antisocial codes for parental reaction included yell, talk, punish, and no action. Punishment primarily took the form of grounding or taking away privileges, and no action was when parents did not take any action against the offense. Prosocial codes for parental reaction included verbal praise, preach/yell, external reward, and no action. External rewards primarily took the form of monetary incentives or gifts.

Adolescent Emotion. We coded responses to parental reactions for adolescent emotions. Antisocial codes for adolescent emotions included happy, angry, guilty, and neutral. Happy responses in antisocial situations were usually accompanied by an explanation of relief due to the fact that the adolescents did not get in as much trouble as they thought they would, and neutral emotions primarily took the form of indifference. Prosocial codes for adolescent emotions included happy, angry, proud, and neutral. ${ }^{1}$ Angry responses in prosocial situations usually reflected the adolescents' desire to receive greater recognition for their positive actions.

Parental Intent. We coded adolescents' views of their parents' intentions for perceived parental intent. Antisocial codes for parental intent included teach, stop behavior, and help/ motivate. Prosocial codes for parental intent included teach, reinforce behavior, and show they care.

Domain. After coded categories were established for both contexts, we divided the vignettes into moral and conventional domains (based on Smetana, 1997; Turiel, 1998) within both antisocial and prosocial contexts, and tabulated frequencies of adolescent responses individually for each of the four contexts (i.e., antisocial/moral, antisocial/ conventional, prosocial/moral, prosocial/conventional). Table 2 shows the mean differences in frequencies of adolescent responses regarding parental reaction, adolescent emotion, and parental intent in moral and conventional domains within antisocial and prosocial contexts. 
Table 1. Final Coding Categories for Parental Reaction, Adolescent Emotion, and Parental Intent in Antisocial and Prosocial Contexts

Parental Reaction:

Antisocial codes and example responses:

Yell: 'He freaked out and yelled at me!'

Talk: 'She sat down and talked to me about what I had done and how we could fix it'.

Punishment: 'He grounded me and took away my car for a week'.

No action: 'He didn't care, they didn't do anything'.

Prosocial codes and example responses:

Verbal praise: 'She congratulated me and gave me a hug'.

Preach/yell: 'She told me I should be worrying about my problems and not other peoples'.

External reward: 'He gave me money'.

No action: 'She didn't even notice, just went on like nothing had happened'.

Adolescent Emotion:

Antisocial codes and example responses:

Happy: 'I felt happy that she wasn't as mad as I thought she would be!'

Angry: 'I was pissed off. He just doesn't understand my point of view'.

Guilty: 'I felt awful for making them worry and was mad at myself'.

Neutral: 'I didn't care. I felt fine'.

Prosocial codes and example responses:

Happy: 'I was happy to be recognized for my efforts'.

Angry: 'I was mad that he always tells me when I do something bad, but didn't recognize that I had done something good'.

Proud: 'I was proud of myself. I'd never done that before'.

Neutral: 'I didn't really care, it was no big deal'.

Parental Intent:

Antisocial codes and example responses:

Teach: 'She was trying to teach me a lesson'.

Stop behavior: 'He didn't want me to do it again'.

Help/Motivate: 'He was trying to help me improve and do better next time'.

Prosocial codes and example responses:

Teach: 'He wanted to teach me how to do it right, or his way'.

Reinforce behavior: 'She was trying to get me to do it again or to repeat the behavior'.

Show they care: 'He just wanted to show me that he cared about me and was thankful'.

\section{Results}

\section{Descriptive Statistics}

A number of univariate ANOVAs were conducted to examine whether demographic variables (e.g., gender, birth order) differed as a function of domain. No statistically significant differences were found except for the gender of the adolescent. Of the 44 ANOVAs run on gender, only two were statistically significant. Females reported more parental yelling 


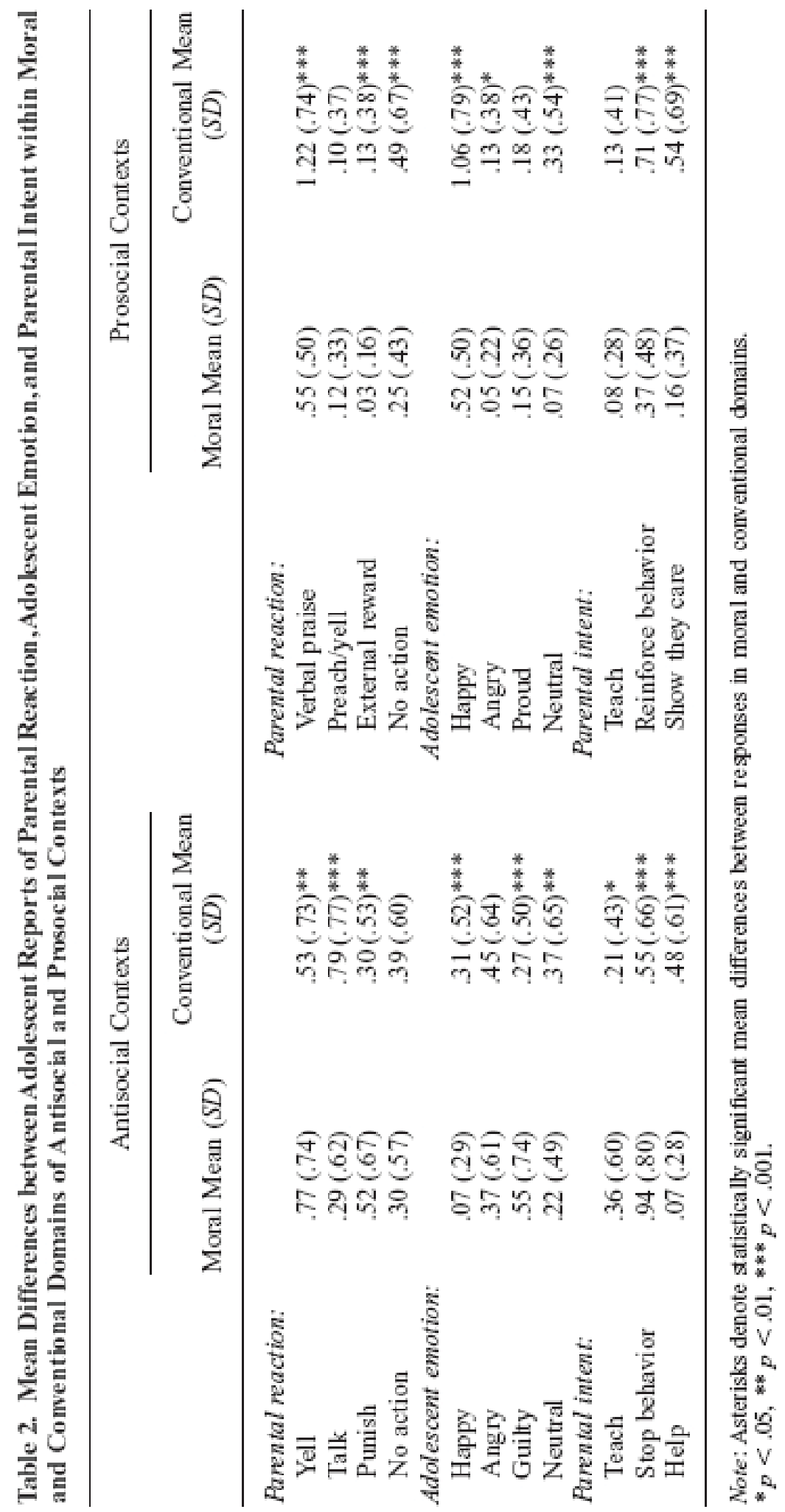


$(\mathrm{M}=.93, \mathrm{SD}=.70)$ in antisocial moral domains than males $(\mathrm{M}=.64, \mathrm{SD}=.74), \mathrm{F}(1,119)$ $=4.81, \mathrm{p}<.05$; and females reported more parental verbal praise $(\mathrm{M}=1.39, \mathrm{SD}=.73)$ in prosocial conventional domains than males $(\mathrm{M}=1.09, \mathrm{SD}=.73), \mathrm{F}(1,119)=4.87, \mathrm{p}<$ .05 .

\section{Differences in Coded Categories as a Function of Domain}

Table 2 presents the means of the adolescent reports of parental reaction, adolescent emotion and parental intent in antisocial and prosocial contexts, and moral and conventional domains. A number of dependent ANOVAs were conducted to determine if there were mean differences in adolescents' perceptions of the parent-child interaction as a function of domain (e.g., moral or conventional).

Antisocial Moral and Conventional Domains. The adolescents reported that parents were more likely to yell, $\mathrm{F}(1,121)=9.24, \mathrm{p}<.01$, partial $\eta 2=.07$, and punish, $\mathrm{F}(1,121)=$ $10.18, \mathrm{p}<.01$, partial $\eta 2=.08$, in antisocial moral domains than in antisocial conventional domains; adolescents were more likely to report feelings of guilt, $F(1,121)=15.38$, $p$ $<.001$, partial $\eta 2=.11$, in antisocial moral domains than in antisocial conventional domains; and the adolescents were more likely to report parental intent of teaching, $F(1,121)$ $=5.60, \mathrm{p}<.05$, partial $\eta 2=.04$, and stopping behavior, $\mathrm{F}(1,121)=21.74, \mathrm{p}<.001$, partial $\eta 2=.15$, in antisocial moral domains than in antisocial conventional domains. The parents were more likely to talk, $\mathrm{F}(1,121)=39.89, \mathrm{p}<.001$, partial $\eta 2=.25$, in antisocial conventional domains than in antisocial moral domains; the adolescents were more likely to report feelings of happiness (or relief), $\mathrm{F}(1,121)=18.06, \mathrm{p}<.001$, partial $\eta 2=.13$, and neutral feelings, $\mathrm{F}(1,121)=7.07, \mathrm{p}<.01$, partial $\eta 2=.06$, in antisocial conventional domains than in antisocial moral domains; and the adolescents were more likely to report parental intent of helping, $\mathrm{F}(1,121)=52.13, \mathrm{p}<.001$, partial $\eta 2=.30$, in antisocial conventional domains than in antisocial moral domains.

Prosocial Moral and Conventional Domains. The parents were more likely to use verbal praise, $\mathrm{F}(1,121)=113.25, \mathrm{p}<.001$, partial $\eta 2=.48$, external reward, $\mathrm{F}(1,121)=8.55, \mathrm{p}$ $<.01$, partial $\eta 2=.07$, and no action, $\mathrm{F}(1,121)=21.97, \mathrm{p}<.001$, partial $\eta 2=.15$, in prosocial conventional domains than in prosocial moral domains; the adolescents were more likely to report feeling happy, $\mathrm{F}(1,121)=54.87, \mathrm{p}<.001$, partial $\eta 2=.31$, angry, $\mathrm{F}(1,121)$ $=4.68, \mathrm{p}<.05$, partial $\eta 2=.04$, and neutral, $\mathrm{F}(1,121)=27.14, \mathrm{p}<.001$, partial $\eta 2=.18$, in prosocial conventional domains than in prosocial moral domains; and the adolescents were more likely to report parental intent to reinforce behavior, $\mathrm{F}(1,121)=22.00$, p < .001 , partial $\eta 2=.15$, and show they care, $F(1,121)=34.60, \mathrm{p}<.001$, partial $\eta 2=.22$, in prosocial conventional domains than in prosocial moral domains.

\section{Differences Between Appropriateness of Parental Reactions as a Function of Domain}

In order to assess which parental reactions were seen as more appropriate as a function of domain, a number of dependent ANOVAs were conducted (see Table 3). Within antisocial contexts, reports of yelling and punishment were rated as more appropriate in moral domains than in conventional domains, and talking was rated as more appropriate in conven- 
Table 3. Differences between Appropriateness of Parental Reactions as a Function of Domain

\begin{tabular}{|c|c|c|c|}
\hline & \multicolumn{3}{|c|}{ Appropriateness in Antisocial Contexts } \\
\hline & $\begin{array}{l}\text { Moral Mean } \\
\quad(S D)\end{array}$ & $\begin{array}{l}\text { Conventional Mean } \\
(S D)\end{array}$ & $F$-test \\
\hline \multicolumn{4}{|l|}{ Parental Reaction: } \\
\hline Yell & $3.52(.96)$ & $2.86(1.08)$ & $(1,48)=22.66 * *$ \\
\hline Talk & $4.12(.86)$ & $4.71(.69)$ & $(1,16)=8.41^{*}$ \\
\hline Punish & $3.37(.94)$ & $2.56(.96)$ & $(1,22)=16.86^{* *}$ \\
\hline \multirow[t]{3}{*}{ No action } & $4.05(1.10)$ & $4.13(.89)$ & $(1,19)=.15$ \\
\hline & \multicolumn{3}{|c|}{ Appropriateness in Prosocial Contexts } \\
\hline & $\begin{array}{l}\text { Moral Mean } \\
\qquad(S D)\end{array}$ & $\begin{array}{c}\text { Conventional Mean } \\
(S D)\end{array}$ & $F$-test \\
\hline \multicolumn{4}{|l|}{ Parental Reaction: } \\
\hline Verbal praise & $4.48(.71)$ & $4.33(.79)$ & $(1,63)=2.82$ \\
\hline Preach/yell & $2.75(.96)$ & $2.88(.85)$ & $(1,3)=.16$ \\
\hline External reward & $4.12(.63)$ & $4.32(.69)$ & $(1,3)=.18$ \\
\hline No action & $4.14(.91)$ & $3.60(1.04)$ & $(1,20)=5.24^{*}$ \\
\hline
\end{tabular}

tional domains than moral domains. Within prosocial contexts, reports of no action were seen as more appropriate in moral domains than in conventional domains.

\section{Correlations with Parental Reactions in Antisocial Contexts}

Table 4 presents correlations conducted to determine how adolescent emotions and parental intentions were associated with different parental reactions in antisocial contexts. To reduce the likelihood of Type I errors and to interpret more meaningful effect sizes, correlations were only considered statistically significant with an alpha level $<.01$. In antisocial moral domains, parental yelling and punishment were positively related to anger, and parental use of no action was positively related to neutral adolescent emotions. Parental punishment was also related to parental intentions of stopping behavior.

In antisocial conventional domains, parental yelling was negatively and parental talking was positively related to happy adolescent emotions. Parental yelling and punishment and parental talking were both positively related to angry adolescent emotions. Parental 


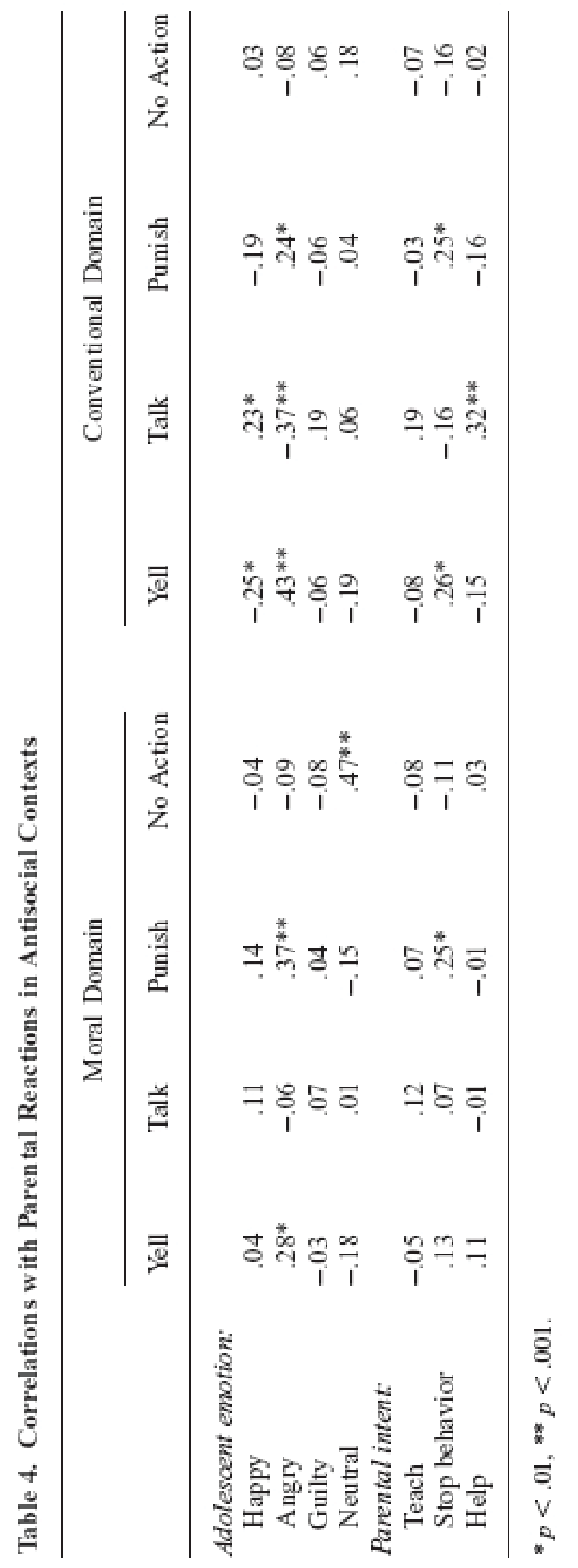


yelling and punishment were positively related to parental intentions of stopping behavior whereas parental talking was positively related to parental intention of helping.

\section{Correlations with Parental Reactions in Prosocial Contexts}

Table 5 presents correlations conducted to determine how adolescent emotions and parental intentions were associated with different parental reactions in prosocial contexts. To reduce the likelihood of Type I errors and to interpret more meaningful effect sizes, correlations were only considered statistically significant with an alpha level $<.01$. In prosocial moral domains, parental verbal praise was positively related to happy adolescent emotions. Parental verbal praise was negatively and parental preaching positively related to angry adolescent emotions. Parental verbal praise was positively and parental no action negatively related to adolescent emotions of pride. Parental verbal praise was positively and preaching negatively related with parental intentions of reinforcing behavior, whereas parental use of external reward was positively related to parental intentions of showing they care.

In prosocial conventional domains, parental verbal praise was positively and parental preaching and no action were negatively related to happy adolescent emotions. Parental verbal praise was negatively and parental preaching and no action were positively related to angry adolescent emotions. Parental use of an external reward was positively related to adolescent emotions of pride. The parental reaction of preaching was positively related to the parental intention of teaching whereas a parental reaction of verbal praise was positively and a parental reaction of no action was negatively related to a parental intent of reinforcing behavior; and a parental reaction of verbal praise was positively and a parental reaction of no action was negatively related to a parental intent of showing they care.

\section{Adolescent Perceptions Associated with Appropriateness as a Function of Domain}

To test the exploratory hypothesis that adolescent perceptions associated with appropriateness would differ as a function of domain, 12 multiple regression analyses were conducted. Analyses were conducted for both moral and conventional domains in both antisocial and prosocial contexts. Separate regressions were run for each general category of predictors, which included parental reaction, adolescent emotion, and parental intent.

Antisocial Context. Table 6 presents the results of six regression analyses designed to examine the adolescents' perceptions of the parent-child interaction that were associated with appropriateness ratings in moral and conventional domains within antisocial contexts. When examining parental reactions, predictors entered simultaneously included yell, talk, punish, and no action. When examining adolescent emotions, predictors entered simultaneously included happy, angry, guilty, and neutral. When examining parental intent, predictors entered simultaneously included teach, stop behavior, and help.

Overall, significant predictors varied based on whether the social domain was moral or conventional. More specifically, within the moral domain, there were two significant regression models. The first model examined parental reaction, Multiple R2 $=.10, \mathrm{~F}(4,110)$ $=3.15, \mathrm{p}<.05$, with yelling negatively related to appropriateness. The second model examined adolescent emotion, Multiple R2 $=.18, \mathrm{~F}(4,110)=6.09, \mathrm{p}<.01$, with reports of feeling happy and guilty positively, and angry negatively, related to appropriateness. The 


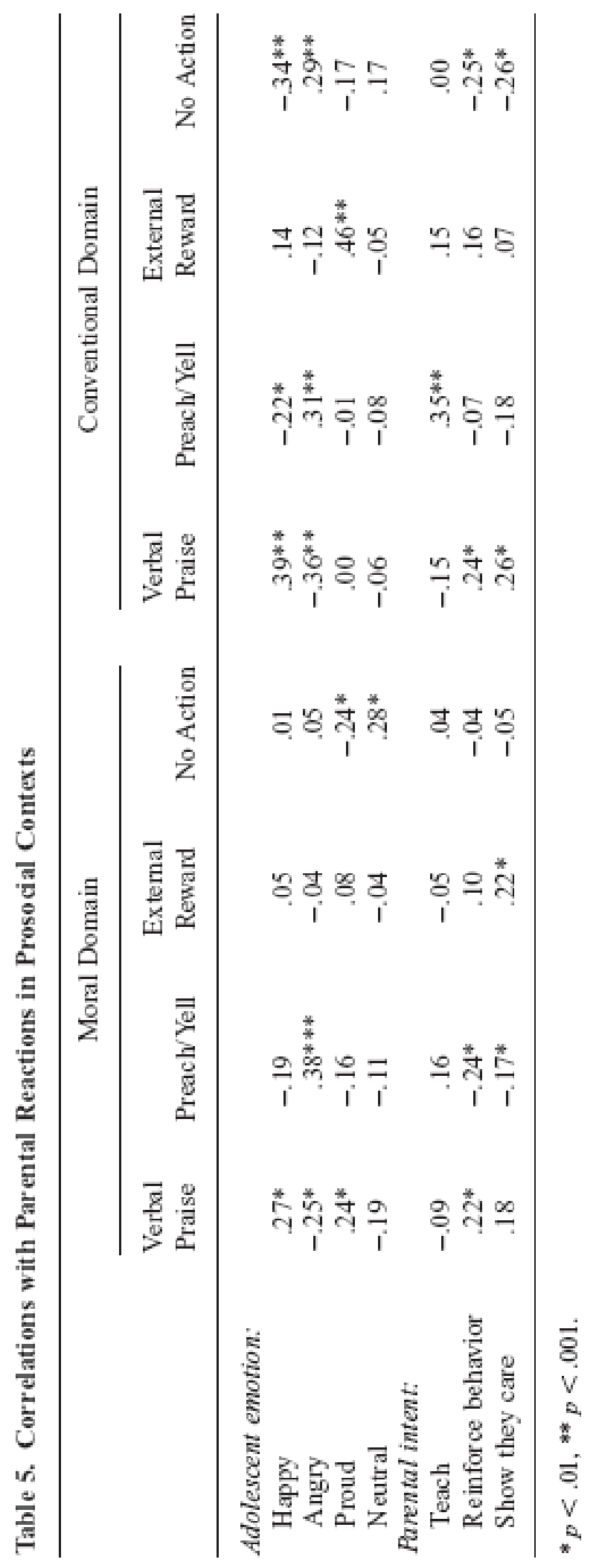




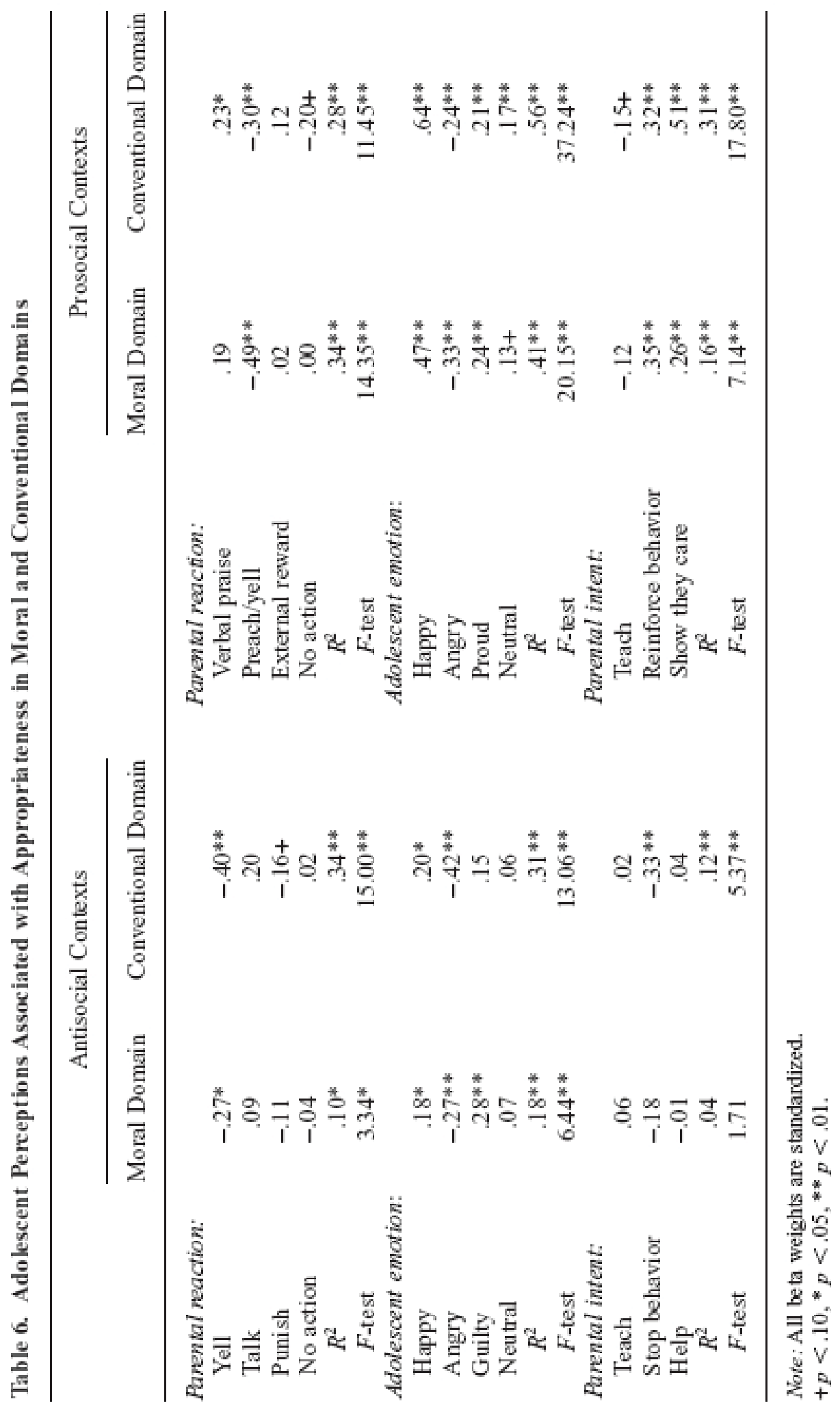


regression model for parental intent was not significant in the antisocial moral domain.

Within the conventional domain, there were three significant regression models. The first model examined parental reaction, Multiple R2 $=.34, \mathrm{~F}(4,116)=15.00, \mathrm{p}<.01$, with yelling negatively related to appropriateness. The second model examined adolescent emotion, Multiple $\mathrm{R} 2=.31, \mathrm{~F}(4,116)=13.06, \mathrm{p}<.01$, with happy positively, and angry negatively, related to appropriateness. The third model examined parental intent, Multiple $\mathrm{R} 2=.12, \mathrm{~F}(3,117)=5.37, \mathrm{p}<.01$, with perceived purpose of stopping behavior negatively related to appropriateness.

These results suggest that yelling and punishment (which was marginally significant) in conventional domains were more strongly associated with appropriateness than in moral domains. Adolescent reports of guilt in moral domains were more strongly associated with appropriateness than in conventional domains. And parental intentions in conventional domains (specifically in controlling intentions) were more strongly associated with appropriateness than moral domains. It should also be noted that the full regression models in the conventional domain accounted were accounting for a relatively greater amount of systematic variance than the full regression models in the moral domain. More specifically, the antisocial conventional regression examining parental reactions associated with appropriateness accounted for roughly three times more variance than the antisocial moral regression; and the antisocial conventional regression examining adolescent emotions associated with appropriateness accounted for roughly two times more variance than the antisocial moral regression.

Prosocial Context. Table 6 also presents the results of six regression analyses designed to examine the adolescents' perceptions of the parent-child interaction that were associated with appropriateness ratings in moral and conventional domains within prosocial contexts. When examining parental reactions, predictors entered simultaneously included verbal praise, preach/yell, external reward, and no action. When examining adolescent emotion, predictors entered simultaneously included happy, angry, proud, and neutral. When examining parental intent, predictors entered simultaneously included teach, reinforce behavior, and show they care.

Overall, significant predictors varied to a small degree based on whether the social domain was moral or conventional. More specifically, within the moral domain, there were three significant regression models. The first model examined parental reaction, Multiple $\mathrm{R} 2=.34, \mathrm{~F}(4,114)=14.35, \mathrm{p}<.01$, with preach/yell negatively related to appropriateness. The second model examined adolescent emotion, Multiple R2 $=.41, \mathrm{~F}(4,114)=20.15$, p $<.01$, with reports of feeling happy and proud positively, and angry negatively related to appropriateness. The third model examined parental intent, Multiple R2 $=.16, \mathrm{~F}(3,115)=$ $7.44, \mathrm{p}<.01$, with the perceived purpose of reinforcing and showing they care both positively related to appropriateness.

Within the conventional domain there were three significant regression analyses. The first model examined parental reaction, Multiple $\mathrm{R} 2=.28, \mathrm{~F}(4,116)=11.45, \mathrm{p}<.01$, with verbal praise positively, and preach/yell negatively, related to appropriateness. The second model examined adolescent emotion, Multiple R2 $=.56, \mathrm{~F}(4,116)=37.24, \mathrm{p}<.01$, with reports of feeling happy, proud, and neutral positively, and angry negatively, related to appropriateness. The third model examined parental intent, Multiple $\mathrm{R} 2=.31, \mathrm{~F}(3,117)=$ $17.80, \mathrm{p}<.01$, with perceived purpose of reinforcing and showing they care both positive- 
ly related to appropriateness.

Although there were few differences in the patterns of variables predicting appropriateness in prosocial contexts across domains, one notable difference was in the regression examining the impact of the parental reaction. Verbal praise in conventional domains was more strongly associated with appropriateness than in moral domains. And no action in conventional domains (which was marginally significant and negatively related to appropriateness) was more strongly associated with appropriateness than no action in moral domains. In addition, adolescent emotions and parental intentions in conventional domains accounted for relatively greater amount of systematic variance than in moral domains.

\section{Discussion}

The goal of the current study was to examine whether adolescents' perceptions of appropriate parental reactions differed across moral and conventional domains, within both antisocial and prosocial contexts. As expected, the frequency of parental reactions, how appropriately adolescents rated parental reactions, and associations between parental reactions, adolescent emotions, and parental intentions differed as a function of domain. Moreover, adolescents' ratings of appropriate parental reactions were more strongly associated with perceptions in conventional domains than moral domains.

\section{Antisocial Contexts}

In antisocial contexts, adolescents reported greater use of parental yelling and punishment in the moral domain than in the conventional domain, and more use of parental talking in the conventional domain. Power-assertive parental reactions (e.g., yelling, punishment) were rated as more appropriate in moral domains than in conventional domains, whereas talking was rated as more appropriate in conventional domains. This is consistent with research suggesting that adolescents are more willing to accept parental discipline in moral domains, or situations where behavior is seen as obligatory, than in conventional domains, where behavior may be seen as arbitrary (Smetana, 1988, 1995). However, although power-assertive parental reactions were seen as more appropriate in the moral domain than the conventional domain, parental yelling was negatively related to appropriateness ratings in both domains. These findings suggest that yelling is related to lower ratings of appropriateness in both moral and conventional domains despite the fact that parental yelling may be seen as more justified in moral domains. These findings provide support for research suggesting that parental yelling is seen by adolescents as an inappropriate parental response across all contexts, and is consistent with research suggesting the disadvantage of using power-assertive parenting practices, placing particular emphasis on the detriment of yelling (Bar-Tal, Nadler \& Blechman, 1980; Hoffman, 2000).

Adolescents also reported higher levels of guilt in the moral domain and higher levels of happiness (relief) and neutral emotions in the conventional domain. Parental yelling in the conventional domain was negatively related to adolescents' happy emotions, but this was not the case in the moral domain. In addition, guilt positively predicted appropriateness in the moral domain, but not the conventional domain. This is consistent with research identifying guilt as an essential emotion in the process of values internalization (Hoffman, 1983, 2000) and extends prior research by suggesting that guilt may not be as strong a factor in motivating compliance in conventional situations. Furthermore, positive 
emotionality might facilitate adolescents' perceptions of the appropriateness of parental reactions in situations that are not obligatory.

Adolescents reported a greater parental intention of teaching and stopping behavior in the moral domain and a greater parental intention of helping in the conventional domain. Also, in the moral domain, parental punishment was positively related to parental intention of stopping behavior whereas in the conventional domain, both parental yelling and parental punishment were related to parental intention of stopping behavior and parental talking was related to parental intention of helping. These findings suggest that adolescents perceive the moral domain as one in which their parents are more likely to try and instruct them or to stop their behavior with punishment, whereas the conventional domain is perceived as one in which parents are more likely to try and help, especially by talking with the adolescent. In addition, parental intentions were not associated with appropriateness in moral domains whereas parental intentions that may be classified as controlling (e.g., stopping behavior) were negatively associated with appropriateness in conventional domains. This suggests that controlling parental intentions are seen as particularly inappropriate in situations where adherence to values is seen as arbitrary, or not in need of regulation.

\section{Prosocial Contexts}

In prosocial contexts, adolescents reported greater use of verbal praise, external reward, and no action in the conventional domain than in the moral domain. It is possible that parents use more verbal praise and reward in the conventional domain because prosocial behaviors are expected in the moral domain and might be more likely to go unnoticed. Indeed, in response to the question 'What was your parent's reaction when you helped out a friend?' one adolescent reported, 'It was no big deal, I am expected to do things like that'. In turn, when adolescents exhibit prosocial behaviors above and beyond what is expected of them (when the action is perceived as a conventional issue), parents might be more likely to notice and acknowledge the behavior. Indeed, adolescents' motivations to perform prosocial behaviors that are not obligatory may be to please the parent or to gain parental attention, as depicted when one adolescent reported, 'I knew that it would make my mom feel good, so I wanted to clean up the house and see how she would react'.

Although parental use of verbal praise was seen as an appropriate response to adolescents' prosocial behaviors in both domains, no action on the part of the parent in prosocial contexts was seen as less appropriate in the conventional domain than the moral domain. In addition, no action from the parent was negatively related to adolescents' happy emotions and positively related to adolescents' angry emotions in the conventional domain, but not the moral domain. This is consistent with research suggesting that children expect greater amounts of praise for behavior that is considered conventional, or discretionary, than they do for behavior that is considered moral, or obligatory (Kahn, 1992). This adds to existing literature by suggesting that not only is more praise expected in conventional domains than moral domains, but when parents are perceived as not responding to prosocial actions, the perceived appropriateness of this response varies as a function of the nature of the domain into which the behavior fits.

Adolescents reported a greater parental intention of reinforcing behavior and helping in the conventional domain than in the moral domain. In addition, parental preaching or yelling in the conventional domain was positively related to parental intention of teaching, 
which was not the case in the moral domain. This suggests that although parental preaching is seen as inappropriate across domains, it may be seen as more positively intentioned (or as a means of instruction) in the conventional domain. In moral domains, parental reaction of external reward was positively related to parental intention of showing they care, whereas in conventional domains, verbal praise was positively and no action was negatively related to parental intention of showing they care. These findings suggest that parental reactions that are associated with adolescents' perceptions of parental intent vary as a function of domain. Thus, the same parental reaction may be perceived by the adolescent as being differently intentioned when used in moral domains than conventional domains.

\section{The Importance of the Conventional Domain}

Interestingly, adolescent emotions and parental intentions were more strongly associated with adolescents' ratings of appropriateness in conventional than moral domains in both antisocial and prosocial contexts (with the exception of parental response in prosocial contexts). This finding suggests that adolescents' perceptions of the parent- child interaction might have a somewhat greater influence on adolescents' feelings and perceptions in situations that are ruled by societal norms and expectations than in situations that are seen as obligatory. Perhaps adolescents have clearer expectations from their parents regarding possible consequences in moral or obligatory situations than in conventional situations, and are therefore not as easily surprised or angered by parental reactions in response to moral misdeeds. For example, when asked how she felt when her parent yelled at her for lying one adolescent said, 'I felt awful, I felt really guilty. I deserved it though, I know that I shouldn't lie'. This is consistent with moral domain research suggesting that children and adolescents consistently judge moral issues as those that should exist in the absence of rules or laws, whereas conventional issues (regardless of importance) are contingent upon social organization (Tisak \& Turiel, 1988; Turiel, 1998). In addition, there are clearer societal sanctions and guidelines in moral situations than conventional ones, and adolescents are more aware of them; thus limiting individual differences in perceptions of appropriateness in moral domains. For example, there are clear societal guidelines regarding honesty, so adolescents may not perceive as great an injustice in being reprimanded for lying as they would for breaking curfew, which is an arbitrary sanction that may vary greatly from one family to another.

\section{Limitations and Future Research}

The present research had a number of limitations, but also raised many questions for future research. Firstly, due to the cross-sectional nature of this research, the direction of effects could not be determined. Further research is needed using longitudinal study designs to better determine direction of effects, especially considering the bidirectional nature of the parent-child relationship (Bell, 1968). Secondly, it is important to study these issues using parent reports as well as adolescent reports. It would be interesting to examine how similarly adolescents and their parents reason and interpret socialization interactions, paying particular attention to prosocial socialization interactions. Indeed, research suggests that adolescents and parents do not always classify situations into the same social domain, and that children find parental reasoning that is more similar to their own to be more appropriate (Grusec \& Goodnow, 1994; Smetana, 1988, 1993; Smetana \& Asquith, 1994). 
Thus, it might be useful to compare adolescent and parent reactions across both moral contexts and social domains, to determine how incongruent perceptions might impact on appropriateness and the relationship between appropriateness and values internalization. And finally, as social domain theorists focus a great deal on the personal domain (Nucci, 1981, 1996; Smetana, 1988, 1993; Smetana \& Asquith, 1994;) as well as moral and conventional domains, and suggest that parents and children are most likely to disagree over behavior in the personal domain, it would be interesting for future research to examine appropriateness in the personal domain.

In conclusion, past research suggests that adolescents' perceptions of the appropriateness of parental reactions differ in antisocial and prosocial contexts (Padilla-Walker \& Carlo, 2004), whereas the current study extends these findings to suggest that adolescents' perceptions of appropriateness also differ depending on the social domain into which the behavior fits. Specifically, the current study draws attention to the importance of adolescents' perceptions of the parent-child interaction in conventional domains. These findings have implications for the effectiveness of specific parenting practices, as well as the impact that perceptions of appropriateness of parental reactions in different domains have on adolescents' internalization of values.

\section{References}

Bar-Tal, D., Nadler, A., \& Blechman, N. (1980). The relationship between Israeli children's helping behavior and their perception on parents' socialization practices. Journal of Social Psychology, 111, 159-167.

Bell, R. Q. (1968). A reinterpretation of the direction of effects in studies of socialization. Psychological Review, 75, 81-95. Bersoff, D. M., \& Miller, J. G. (1993). Culture, context, and the development of moral accountability judgments. Developmental Psychology, 29, 664-676.

Carlo, G. (2006). Care-based and altruistically-based morality. To appear in M. Killen, \& G. Smetana (Eds.), Handbook of moral development (pp. 551-579). Mahwah, NJ: Lawrence Erlbaum Associates.

Eisenberg-Berg, N., \& Geisheker, E. (1979). Content of preachings and power of the model/ preacher. The effects on children's generosity. Developmental Psychology, 15, 168-175.

Grusec, J. E., \& Goodnow, J. J. (1994). Impact of parental discipline methods on the child's internalization of values: A reconceptualization of current points of view. Developmental Psychology, 30, 4-19.

Grusec, J. J., Goodnow, J. J., \& Kuczynski, L. (2000). New directions in analyses of parenting contributions to children's acquisition of values. Child Development, 71, 205-211. Helwig, C. C., Tisak, M., \& Turiel, E. (1990). Children's social reasoning in context. Child Development, 61, 2068-2078.

Hoffman, M. L. (1983). Affective and cognitive processes in moral internalization. In E. T. Higgins, D. N. Ruble, \& W. W. Hartup (Eds.), Social cognition and social development: A sociocultural perspective (pp. 236-274). Cambridge: Cambridge University Press.

Hoffman, M. L. (2000). Empathy and moral development: Implications for caring and justice. Cambridge: Cambridge University Press. Kahn, P. H., Jr. (1992). Children's obligatory and discretionary moral judgments. Child Development, 63, 416-430.

Killen, M., Lee-Kim, J., McGlothlin, H., \& Stangor, C. (2002). How children and adolescents evaluate gender and racial exclusion. Monographs of the Society for Research in Child Development, 67, (4, Serial No. 271).

Nucci, L. (1981). The development of personal concepts: A domain distinct from moral or societal concepts. Child Development, 52, 114-121. 
Nucci, L. (1984). Evaluating teachers as social agents: Students' ratings of domain appropriate and domain inappropriate teacher responses to transgression. American Educational Research Journal, 21, 367-378.

Nucci, L. (1996). Morality and personal freedom. In E. Reed, E. Turiel, \& T. Brown (Eds.), Knowledge and values (pp. 41-60). Hillsdale, NJ: Erlbaum.

Padilla-Walker, L. M., \& Carlo, G. (2004). 'It's not fair!' Adolescents' constructions of appropriateness of parental reactions. Journal of Youth and Adolescence, 33, 389-401.

Smetana, J. G. (1988). Adolescents' and parents' conceptions of parental authority. Child Development, 59, 321-335.

Smetana, J. G. (1993). Conceptions of parental authority in divorced and married mothers and their adolescents. Journal of Research in Adolescence, 3, 19-40.

Smetana, J. G. (1995). Context, conflict and constraint in adolescent-parent authority relationships. In M. Killen, \& D. Hart (Eds.), Morality in everyday life (pp. 225-255). New York: Cambridge University Press.

Smetana, J. G. (1997). Parenting and the development of social knowledge reconceptualized: A social domain analysis. In J. E. Grusec, \& L. Kuczynski (Eds.), Parenting and children's internalization of values: A handbook of contemporary theory (pp. 162-191). New York: Wiley.

Smetana, J. G., \& Asquith, P. (1994). Adolescents' and parents' conceptions of parental authority and adolescent autonomy. Child Development, 65, 1147-1162.

Smetana, J. G., Bridgeman, D., \& Turiel, E. (1983). Differentiation of domains and prosocial behavior. In D. L. Bridgeman (Ed.), The nature of prosocial development: Interdisciplinary theories and strategies (pp. 163-183). New York: Academic Press.

Tisak, M. S. (1995). Domains of social reasoning and beyond. In R. Vista (Ed.), Annals of child development (Vol. 2, pp. 95-130). London: Jessica Kingsley.

Tisak, M. S., \& Turiel, E. (1988). Variation in seriousness of transgressions and children's moral and conventional concepts. Developmental Psychology, 24, 352-357.

Turiel, E. (1983). The development of social knowledge: Morality and convention. Cambridge: Cambridge University Press.

Turiel, E. (1998). The development of morality. In N. Eisenberg (Ed.), Handbook of child psychology: Vol. 3. Social, emotional, and personality development (5th ed., pp. 863-932). New York: Wiley.

Wyatt, J., \& Carlo, G. (2002). What will my parents think? Relations among adolescents' expected parental reactions, prosocial moral reasoning, and prosocial and antisocial behaviors. Journal of Adolescent Research, 17, 646-666.

\section{Acknowledgments}

The current study was conducted while the first author was at the University of Nebraska-Lincoln. The authors appreciate the co-operation of the teachers, staff, and students of Lincoln Southeast High School, especially Rob McEntarffer. Funding support for this project was provided to the second author by grants from the John Templeton Foundation and the American Psychological Association.

\section{Note}

1. It should be noted that on occasions when adolescents reported emotions, it was apparent that they were responding not to their parents' reaction, but to their own behavior. This was the case most saliently with the emotion of pride, thus the findings regarding adolescent emotions of pride should be interpreted with caution. 